\title{
Some Background, and a South African Study on Sexuality
}

Xanthe Hunt, Leslie Swartz, Stine Hellum Braathen,
Mark T. Carew, Mussa Chiwaula, and Poul Robleder

- 33 times lovestruck celebrities made us go "Aww" (msn.com/en-za)

- Can using weed affect my sexual performance? (timeslive.co.za)

X. Hunt $(\varangle)$

Department of Psychology, Faculty of Arts and Social Sciences, Stellenbosch University, Stellenbosch, South Africa

Institute for Life Course Health Research, Department of Global Health, Faculty of Medicine and Health Sciences, Stellenbosch University, Stellenbosch, South Africa

L. Swartz

Department of Psychology, Faculty of Arts and Social Sciences, Stellenbosch University, Stellenbosch, South Africa

e-mail: Lswartz@sun.ac.za

S. H. Braathen

Department of Health Research, SINTEF Digital, Oslo, Norway

e-mail: stine.h.braathen@sintef.no

(C) The Author(s) 2021

X. Hunt et al. (eds.), Physical Disability and Sexuality, https://doi.org/10.1007/978-3-030-55567-2_1 
- Should local celebrities be encouraging people to find romantic partners on Linkedin and other professional networks? (news24.co.za)

- Is \#MeToo casting a shadow on sexual pleasure? (iol.co.za).

These headlines were taken from home pages of major South African news sites on Wednesday 3 April 2019-the date on which we happened to be writing this introductory chapter.

Sex and sexuality seem to be everywhere-they are all over the media, a concern for everyone growing up, celebrated by some and condemned by others. It is not possible to open a newspaper or popular website without some discussion of sex. Though many people may say that sex is a taboo, the fact is that we cannot stop talking about it. According to Alexa.com (also accessed on 3 April 2019), which tracks website use, pornhub.com (a Youtube-like platform for pornographic videos) is the 27th most visited website globally, and 24th most visited website from South Africa. Many popular magazines aimed at men or women, or both, will regularly have tips for readers on how to be more sexy, or have more sex; many have columns devoted to people writing in with complaints about their sex lives (or lack thereof).

Sex and sexuality are not just matters of biology. When we use the term "sexuality", some might think of the physical acts of sex, or sexual orientation (e.g. being gay or lesbian), or about someone's gender or gender identity (e.g. being transgender or identifying as a man or woman or neither or both). In this book, we use the term "sexuality" to refer more

\author{
M. T. Carew \\ UCL International Disability Research Centre, Department of Epidemiology \\ and Public Health, University College London, London, UK \\ e-mail:m.carew@ucl.ac.uk \\ M. Chiwaula \\ Southern African Federation of the Disabled, Gaborone, Botswana \\ e-mail: mchiwaula@safod.net \\ P. Rohleder \\ Department of Psychosocial and Psychoanalytic Studies, University of Essex, \\ Colchester, UK \\ e-mail: p.rohleder@essex.ac.uk
}


broadly to the experience and quality of being sexual. The World Health Organisation (2006) provides a useful, broad definition of "sexuality" as:

... a central aspect of being human throughout life and encompasses gender identities and roles, sexual orientation, eroticism, pleasure, intimacy and reproduction...influenced by the interaction of biological, psychological, social, economic, political, cultural, legal, historical, religious and spiritual factors. (WHO, 2006, p. 5)

As this definition suggests, the way in which we experience our sexuality, sexual urges, arousal and so on is very much shaped by what society and the cultural context that we are in understands about sexuality. Thus, society shapes the way in which our sexuality is expressed: we learn whether we are sexy, or not, in the eyes of others, and whether we are deemed fit to participate in sexual relationships. Very often, societal views involve expressions of power and control. We can see this, for example, in the many strongly held views that people in various societies may have about who should have sex with whom, how they should have sex, where and when they should have sex. We can see this when it comes to homosexuality, for example, where, in many parts of the world, homosexuality is regarded as an abnormality and abomination, punishable by law in some countries. At the time of writing this chapter, Brunei had recently brought in new laws bringing in death by stoning for having "gay sex". Meanwhile, in other societies, homosexuality is regarded as a normal expression of human sexuality, and - at the time of writing - Taiwan's parliament has recently legalised marriage between persons of the same gender. When it comes to sexuality, context, culture and social norms play a huge role, and as you will see, this role is not neutral, nor always rational or fair. In this book we also address gender and gender identity, but these are defined and discussed in depth elsewhere (see Chapters 4 and 6), as well as the more health-related aspects of sexuality, including sexual and reproductive health (see Chapter 8).

For people with disabilities, participation in sexual life is often complicated. This complication stems more from the attitudes of the world "out there" than the physical or psychological impairment of the individual. Social views about what is "normal" sexuality and what is not, what is acceptable and what is not, impact on how we view the sexual lives of people with disabilities. The sexuality of people with disabilities, including people with physical disabilities (with whom this book is 
concerned), has been a site of oppression and discrimination, based on many myths and misconceptions. Prevailing myths are, for instance, that people with physical disabilities are unable to have sex, experience less or no sexual desire, or lack the capacity for parenthood and should not baer children (Malacrida, 2009; Nguyen, Liamputtong, \& Monfries, 2016). Additionally, societal understandings of masculinity and femininity, bodies and attractiveness, often lead to people with visible disabilities being seen as undesirable romantic or sexual partners (Hergenrather \& Rhodes, 2007; Marini, Chan, Feist, \& Flores-Torres, 2011). These sorts of attitudes represent social barriers excluding people with disabilities from full participation and enjoying fully sexual lives.

These attitudes also have implications for sexual and reproductive health (de Reus, Hanass-Hancock, Henken, \& van Brake, 2015; Groce et al., 2013; O'Dea, Shuttleworth, \& Wedgwood, 2012; Peta, 2017). Because of problematic prevailing attitudes, people with disabilities may be perceived as not in need of sexual and reproductive health care, or may not be able to access such care easily. Additionally, people with disabilities may be considered by some as vulnerable targets for abuse. These issues have negative implications for many people with disabilities in South Africa, a country with a high prevalence of human immunodeficiency virus (HIV), where the latest findings from the country's Human Sciences Research Council-published national household survey on HIV prevalence in South Africa (Leonardi, Bickenbach, Ustun, Kostanjsek, \& Chatterji, 2006; WHO, 2001; WHO and The World Bank, 2011) indicate that people with disabilities (inclusive of all types of disabilities) may be at increased risk for acquiring HIV.

The adoption of the Convention on the Rights of Persons with Disabilities (UNCRPD) by the United Nations (United Nations, 2006), in 2006 formalised a new way of thinking about disability - the human rights approach to disability. Article 25 of the UNCRPD emphasises the need for government parties to recognise that people with disabilities have the right to the enjoyment of the highest attainable standard of health without discrimination on the basis of disability, including sexual and reproductive health. Governments are called upon to take all appropriate measures to ensure access for people with disabilities to health services that are gender-sensitive. The UNCRPD has been in place now for a little over a decade and some remarkable progress has been made in improving the rights of people with disabilities. Most countries in Southern Africa have ratified the UNCRPD. However, what remains to be achieved is the domestication of this human right instrument so that it becomes 
meaningful in terms of contributing to change in the lives of people with disabilities, including in respect to sexuality, and sexual and reproductive health.

In the spirit of the UNCRPD, awareness campaigns need to be developed and put in place in mitigating the falsehood that people with disabilities are, or should be non-sexual, and people with disabilities need to be enabled to access information regarding sexual reproductive health and HIV. This would give people with disabilities the ability to make informed personal decisions about all matters pertaining to their sexuality, as well as to their reproductive health rights, on an equal basis with people without disabilities.

Given the prevailing myths and misconceptions that exist, this book is intended to raise awareness of these issues, by drawing on materials produced from a research project exploring the experiences of some men and women with physical disabilities in South Africa, as well as on past research from around the world and on survey research conducted by the editors.

This book focuses on people with physical disabilities, because the research project which inspired us to write it focused exclusively on people with physical disabilities. The reason for this was that the project aimed to focus on exploring and challenging the myth that people with disabilities are less sexual than people without disabilities. Thus they are perceived by many people without disabilities to be asexual (even if they do not identify as such). In past research, this myth is more attributed to people with visible, physical disabilities, than other impairment types, and so our project, and this book, have concerned themselves only with physical disability.

The project also made use of visual materials (photographs and film) and so it made sense to focus on visible, physical disabilities, rather than other types of disabilities which may be less visible, or hidden.

This book, written co-operatively by academics, advocates, and people with physical disabilities who participated in our study, contains informative chapters about different topics related to physical disability and sexuality. The style and presentation of the book differs from a traditional research, theoretical or academic book in that it synthesises contemporary scholarship and theorising on disability and sexuality, with personal narratives and photographs. We have also tried to write it in language which is accessible to people who are not familiar with disability studies as a field. 
Our intention, in doing this, is for the book to be of interest to both non-academic and academic audiences. The aim of the book is to provide you, the reader, not only with a research-based account of what impact disability has on the sexual lives of people with physical disabilities, or the impact of people without disability on the sexuality of people with disabilities, but also to provide this account from the personal, lived experiences of South Africans with physical disabilities themselves, so that you may know what these experiences are like from an "insider's" perspective. We hope that you will use this book to learn something new, and perhaps think about disability and sexuality, and indeed your own body and sexual self, in a different way.

Before we continue, we will pause to think about the various ways we can understand disability, and what it is. We will then tell you about the project that this book is based on, who the people involved are and what we did. Finally, we will provide an outline for the remainder of the chapters so that you have a sense of what you will be reading about in the rest of this book.

\section{What Is Disability?}

As sime as it may seem, the issue of defining disability is not a straightforward question, and it depends very much on where the experience of disability is located, from whose perspective and in which context. So, for example, would we say a person who makes use of a wheelchair is "disabled" because he or she uses a wheelchair? Or is he or she disabled because they cannot access a building because the way in is up a set of steps? A person who uses a wheelchair may be perfectly "able" to do many things, but may be "disabled" when they are excluded or prevented from doing other things. If that building had a ramp, the person using a wheelchair would then be "able" to enter and make use of the space, and so does the term "disabled" accurately describe them? Much of our understanding about disability often involves some sort of comparison to what is "normal". But what we regard as "normal" is not straightforward. "Normality" is shaped by contextual, cultural and individual experiences, beliefs and realities, and is a constantly changing concept. Thus, what is "normal" is not an absolute truth. So, for example, we have typically built buildings with steps leading up to the front door, because we have designed them around the needs of only those people who can walk up these steps, rather than use a ramp that is accessible 
to far more people. The steps do not have to be there; it is a choice to put in steps, rather than a ramp. This state of affairs is true for many things related to disability: disabling experiences are created by environments which are designed for people without disabilities. Disability is not inherently abnormal, but society is organised in such a way that makes it seem so.

You may still be confused. In fact, there is a lot of debate among theorists about how disability is to be understood. Two of the most frequently used models for understanding disability are the medical model and the social model. The medical model frames disability as being caused by some underlying biological or medical cause - a biological or psychological impairment caused by a disease or disorder. This can be represented in a diagram like this (Fig. 1.1).

In this model, disability is something that is located "inside" the individual, and can only be "fixed" by changing the underlying disease or disorder through medical intervention. Here, it is the body that needs to be "fixed".

In contrast, the social model of disability takes into account the role of the environment and sees the experience of "impairment" and "disability" as different. In this model, a person with an impairment experiences "disability" when he or she faces barriers to participation. This can be represented in a diagram like this (Fig. 1.2).

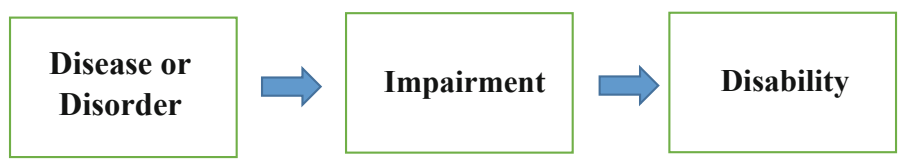

Fig. 1.1 A representation of the medical model of disability (Author's own)

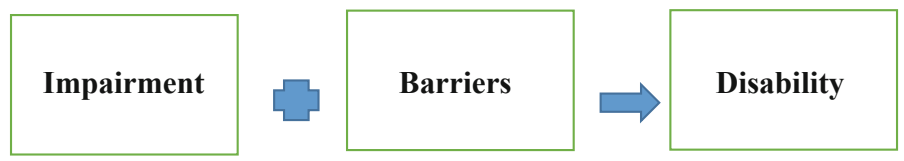

Fig. 1.2 A representation of the social model of disability (Author's own) 
In this model, disability is located in the environment, not the individual. Disability is diminished by making changes to the environment which allows people with impairments equal opportunities to participate. So, a person may have an impairment, but not necessarily experience a disability. So for example, let's take the experience of Mandla, below (we explain the use of names and pseudonyms later in this chapter). Here he talks about the changes that needed to be made to the physical environment at his work to make spaces accessible to him, so that he would not experience "disability".

\section{Mandla's story}

Mandla acquired a disability following a car accident in 2010. He became partially paraplegic. He can sometimes walk using crutches, and at other times makes use of a wheelchair. There had not been a person with disability employed at his place of work before, so the employers had to make adjustments to the physical environment to make the buildings and facilities accessible to him when he returned to work after his accident. Here he took a photograph of a ramp which was purposely built for him leading from the car park to the entrance of the building (see below section on "about the disability and sexuality project" for an explanation of where these photographs and personal stories come from). Mandla says:

Ja, when I was doing these pictures...because I only took the ones for the parking, front and back...and some people asked me why are you taking pictures? Where are you going to take them? You know, they are scared you're going to take them to human rights and all those things. But I said, no, I'm taking these photos for my project. I'm trying to show what you have done for me. You've done a lot. You've made so many changes within a few months, which means you've accepted me from the first day I arrived at this point. And then when I came to you and said, listen here, I've got this plan, but I need to sit down and talk to you about it, then you said to the HR officer to come and talk to us about how must we make changes in this building for it to be accessible for you. I told them, firstly, there must be ramps. The first thing is the ramps. There must be ramps in this building. And then the toilets, there must be a disabled toilet as well in this building. And in terms of movement, there must be no place where I can't walk in because of the wheelchair. There must be no place whereby you say, no, this place is not accessible to wheelchairs. Because sometimes you're going to get visitors from outside coming here, wheelchair-bound people coming here, and then they will be stuck and what's going to happen then? How are you going to explain that? So I want you to make changes. The parking, there must be disabled parking because sometimes you get visitors driving cars. The other thing I must tell you, people who are physically disabled, 
they can drive. You must know they can drive. Because cars can be made for people with disabilities. So if you've got a spinal cord injury and your legs can't work properly, you can still drive. There are automatic cars and everything. So they've made the parking. They just phoned maintenance and they came and just made the parking. And then the toilet, they had to revamp another toilet to be a disabled toilet. Ja, so many changes. And the gymnasium as well, they had to make a ramp there. So, so many changes in a few months. You see this ramp? If you look at it, it must look like this. You can see it was specially made as well, the ramp. There was no ramp. It was just the step. Now everyone is using this because it's next to the disabled parking. These two parkings are disabled parkings. So they had to revamp here again to make this thing accessible for me. You can see the wheelchairs can run smoothly here. Because you park here, and there's a disabled parking this side and that side. So if you park here, you don't have to push the wheelchair from the parking. You park here next to the entrance, then you just walk in there. You can see that it's me standing there.

More recently, theorists have stated that both the medical model and the social model are too simplistic, and pointed to the need to consider how these different aspects of a person's experience interact with one another. The biopsychosocial model, presented in the International Classification of Functioning, Disability and Health (ICF) developed by the World Health Organisation (2001), understands disability as both a social and medical construct, highlighting its interactive and dynamic nature. This model acknowledges both individual health status as well as personal and environmental (cultural and contextual) factors in the disability experience (Shisana et al., 2014). So, in this model, disability is not only seen as located in the individual (like the medical model) or the environment (like the social model), but as an interaction of both. Nico's photograph and story below can help us to understand this a little. Here Nico talks about the freedom that he sees people without disability have to move and do what they want. He talks about how some of his freedom is taken away by social attitudes (the environment), but he also talks about how his impairment makes it difficult for him to participate without help and assistance, and so he cannot be feel fully "free", regardless of how the environment is arranged. He captures here how it is both his body and the environment in interaction that makes him experience disability (Image 1.1). 


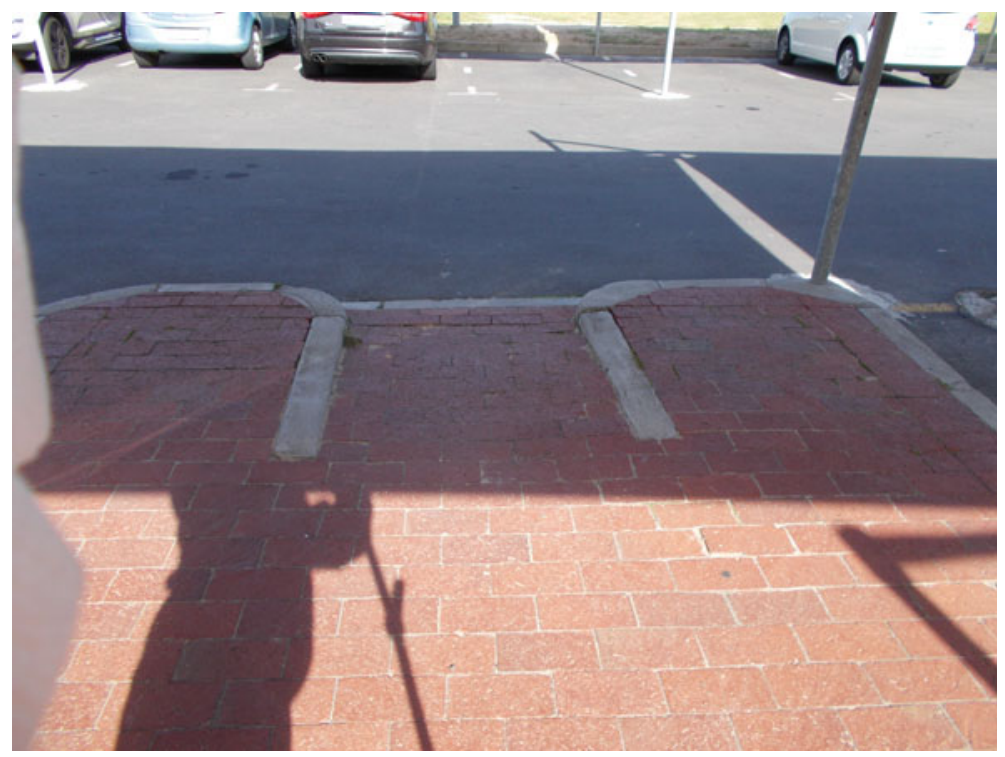

Image 1.1 An accessible parking lot ramp built for Mandla by his employers, following his acquiring a physical disability (Photo by Mandla)

\section{Nico's story}

Nico is a 25 -year old man who acquired a disability following an accident when he was 18. The accident left him semi-paraplegic, requiring him to use a wheelchair. Here he took a photo of a female friend in a pool, which to him represents his experience of (not having) freedom. Nico says:

...this everybody desires. Besides the water, but look at the picture itself and the lady; that you call freedom, in the sense that people who are physically disabled, they also need the freedom to express themselves. They need to bind with non-disabled people for the understanding-wise. Sometimes people are always judging and criticising those who don't look in a perfect manner for them. The reason why I took this is also just to show the reflection of the water and this lady going into that water freely; jumping in that water. They can do what they want to do in the water. But now talking about myself again - I like to give an example of myself - standing at the edge of the water and telling myself I can go in that water, but how am I going to balance myself? Who is going to assist me? Who is going to guide me through this whole process where that non-disabled person can 


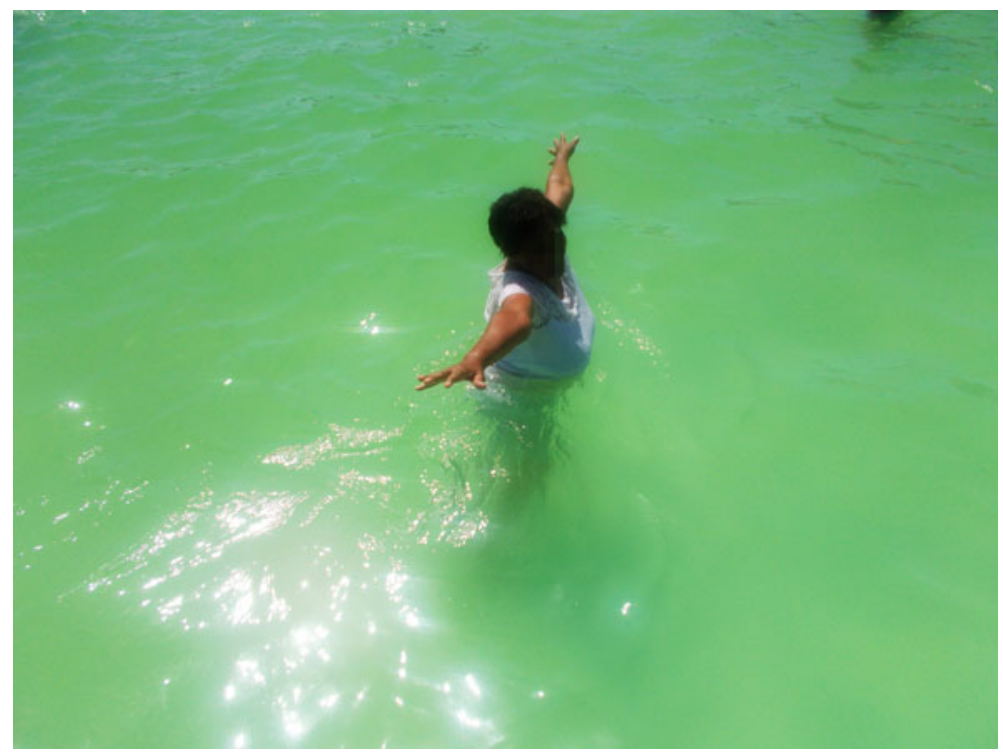

Image 1.2 A photo of a woman in a white t-shirt swimming in the ocean, taken by Nico (Photo by Nico, previously published in the chapter by Hunt, X., Swartz, L., Braathen, S. H., Carew, M., Chiwaula, M., \& Rohleder, P. (2019). Shooting back and (re) framing: Challenging dominant representations of people with physical disabilities in South Africa. In Diverse voices of disabled sexualities in the global south [pp. 33-53]. Cham: Palgrave Macmillan)

contribute his or her help according to my need? That is what I'm working with here. (Image 1.2)

\section{Disability in South Africa}

This book highlights the experiences of people with physical disabilities in South Africa, because that is where we conducted our project. The stories depicted here are not reflective of the experiences of all people with physical disabilities, nor of all South Africans with disabilities, and only provide a small snapshot of life for some people with physical disabilities in a certain social, political, economic and cultural context. The stories of people with disabilities from the global South, however, are particularly 
important, and so that is why our study was not done in a high-income country. Across the world, the large majority of people with disabilities live in low- and middle-income countries, most of which are located in the global South (WHO \& World Bank, 2011). However, much of the research on disability, sexuality, sexual and reproductive health is conducted in North America and Western Europe (Braathen, Rohleder, \& Azalde, 2017; Carew, Braathen, Swartz, Hunt, \& Rohleder, 2017). Thus, less is known about the sexual lives of people with disabilities from the countries and regions where they are most likely to live.

In a 2014 report based on the 2011 South African census data (Statistics South Africa, 2014), 7.5\% of South Africa's population was reported to have a disability; an estimated 2.87 million people, $59 \%$ of whom were reported as female and $41 \%$ male. People with disabilities in South Africa have significantly lower levels of education and less access to education than people without disabilities. People with disabilities are also more likely to be unemployed and earn generally lower levels of income than people without disabilities. Thus, people with disabilities in South Africa are among the most marginalised groups, as is the case throughout the world.

This is attributable to social and economic structures being exclusionary of people with disabilities, and not to some limitation of people with disabilities themselves. If you only read one sentence in this book, read this one.

Now, while this book is based on the experiences of South Africans, it is worth noting that it has some limitations in relation to its origins; the people presented in this book are not representative of the majority of South Africans. Because the participants in our study volunteered themselves to write and take photographs and share their stories, we did not have control over the types of people who were included, nor did we try to take this control. As such, we have a group of men and women who all identify as heterosexual and cisgender, when we know that some South Africans with physical disabilities also identify as LGBTQ+ and transgender. Our participants also identify with a variety of ethnic, cultural, religious and socio-economic backgrounds, but as a small group they are not representative of the demographics of the country as a whole. Their stories are invaluable, and their value lies not in their representativeness of demography, but, rather, of emotional and social experience. Their stories may not always include insights with South African specificity, and as Southern researchers, the editors of this book are careful not to make 
any demands of participants to perform Southern-ness, when the stories they wanted to share were somewhat universal.

Still, as editors, we would like to highlight the necessity of future work on the topic of sexuality and disability in the country. This could usefully also create a platform for the voices of people from other ethnic, cultural, and socio-economic backgrounds, and other geographic areas, as well as other gender identities and sexual orientations. The value of research like this is in diversity and representation; so more work is always needed.

\section{About the Disability and Sexuality Project}

As noted, this volum has been produced from a research project that the editors of this book conducted between 2015 and 2017. The project was funded by the International Foundation of Applied Disability Research (www.firah.org), and one of the editors was supported by the National Research Foundation of South Africa (NRF). The project was developed from the existing work of the editors, who have previously done research or development work on disability, inclusion and health. The project was then run, in part, by the first editor of the book, whose Ph.D. concerned certain aspects of the research (see the Foreword for details).

The Disability and Sexuality Project explored prevailing myths and attitudes towards the sexuality of people with physical disabilities in South Africa. As mentioned above, a major social barrier for people with physical disabilities to live full sexual lives is the belief that people with disabilities (such as physical disabilities) are asexual (even if they do not identify as such), and are thus not perceived as sexual people. Asexuality is a valid sexual identity; but like any other, it should not be imposed on people from the outside, and it is the imposition with which we are concerned. The Disability and Sexuality Project was a collaborative, creative research project which aimed to:

- investigate the attitudes of the general population towards the sexuality of people with disabilities in South Africa;

- explore the experiences of stigma and barriers to, as well as facilitators of, fulfilling sexual relationships, as well as other aspects of sexuality, among people with disabilities in South Africa; and

- raise public awareness about the intersection between disability stigma and sexuality. 
As a research project we adopted the method of "participatory action research", which is an attempt to do research not on the people being studied (in this case people with physical disabilities), but rather with them; with their active participation in designing the study and collecting data and reporting on findings. In doing so, we are trying to do research in a way that also takes action to promote inclusion and bring about change. It also foregrounds those who are experts in the topic (people with physical disabilities) in work concerning them. This book is one of the project's products. So what is participatory action research?

\section{Participatory Action Research}

There are many ways in which to do participatory action research. Participatory action research does not refer to a specific method, but rather an approach to research. In such an approach, the aim is to generate knowledge and create actions on issues that affect people or communities, by means of a process of participation with the very people or communities it seeks to benefit (Kagan, Burton, \& Siddiquee, 2008). In this approach, research is conducted as a team effort, not just by a team of researchers and academics, but with multiple partners, including stakeholders and research subjects. In this approach, research is done by researchers "working alongside the primary sources of knowing" (Goodley \& Lawthom, 2005, p. 136). Furthermore, the aim is not just to conduct research for the sake of learning something (i.e. generate knowledge), but also to do something with that knowledge that brings about some social change (i.e. take action).

Participatory action research developed in various parts of the world, including South America, the United States of America (USA) and the United Kingdom (UK), as a way of addressing social problems and social inequalities. For example, in the 1940s in the USA, participatory action research was adopted as a way of investigating intergroup relations in real-life contexts, in order to generate understanding and bring about improvements in the lives of Indigenous Americans (Collier, 1945). In the UK, participatory action research developed as a means of responding to the social and mental health problems caused by the aftermath of the Second World War (Rapoport, 1970). In South America, the educationist Paulo Freire (1972) has been a very influential writer in participatory action research. He argued that learning can only take place when there is active dialogue between multiple parties, sharing ideas and points of view. 
Lewin (1946), one of the early developers of participatory action research as an approach, described it as a cyclical process of inquiry and learning. In such a process, initial exploration of an issue will inform the planning of action steps to be further taken. The learning that takes place as a result of those first action steps then further informs the development of new action steps. Thus, through a process of learning, taking action, evaluating the results of that action, and taking further steps, change can start to occur. Important in this process is that multiple stakeholders have input at all these stages, rather than just the research team. Ideas, issues and action steps are explored collaboratively with all partners (both researchers and other stakeholders).

Participatory action research involves the active participation of stakeholders. However, "participation" can mean many things, and can include just sharing information, or consulting on issues of importance, to deciding and acting together on what should be done and how to do it. A useful way of thinking about degrees of participation is to think about it along two different axes (Kagan, Burton, Duckett, Lawthom, \& Siddiquee, 2011):

passive participation $<<<>>>$ proactive participation

low commitment $<<<>>>$ high commitment.

So, with research related to issues of disability, people with disabilities may "participate" as members of an advisory board, which we could think of as a relatively low level of participation (passive participation) with minimal commitment. Where people with disabilities act as equal partners in the research process, this would be a high level of participation with maximum commitment.

Participation was a key feature of the Disability and Sexuality Project from the very start. The editors of the book comprised the core research team, which included academic researchers as well as stakeholders from civil society (from the Southern African Federation of the Disabled). The core research team consisted of members with disabilities and members without disabilities. As a core research team, we led on the design, planning and implementation of the research project, the collection and analysis of data, and the dissemination of findings. However, we also invited the active participation of the research "subjects", thirteen South African men and women with physical disabilities. In the book we use the term "participants" to refer to the people with disabilities we interviewed, 
but this does not imply that they were passive subjects being studied, and in this book, many are co-authors.

\section{What We Did}

The project adopted a mixed method design, using both survey and qualitative individual interview methods for collecting data. We got ethical approval to conduct the research from the University of East London (in the UK) and Stellenbosch University (in South Africa). The project involved two complimentary studies:

\section{Study i: A Survey of Societal Attitudes}

An online survey was developed to explore the knowledge, attitudes and views of the "general" South African population about physical disability and sexuality. The survey included questions measuring prevailing myths about disability and sexuality, and attitudes about the sexual and reproductive health and rights of people with physical disabilities. In Chapter 2 we presented some results of this survey study.

There are many ways in which to design a survey questionnaire, but what was important in putting together a questionnaire about disability and sexuality was not only designing a questionnaire that had sound research principles, but that also reflected what persons with physical disabilities themselves identify as important areas to focus on. At the start of the project, we held a participants' workshop, where 18 people with physical disabilities who had expressed an initial interest in participating in the project took part. At this workshop, the Disability and Sexuality Project was presented, and the project aims and objectives were discussed. The workshop included a session on thinking about the survey to be conducted, generating ideas for what sorts of questions should be asked, and how. This had to be discussed in the form of a dialogue between academic researchers, who had particular sets of knowledge about how research surveys should be designed, and non-academics, who may have had strong ideas about what should be asked, but did not necessarily have the knowledge about how good survey questionnaires should be designed. What proved useful was for the core research team to give a presentation about designing surveys and the various forms of questions that could be included (e.g. questions that invited scored answers on a scale from 1 to 7 , questions that invited an open reply, or questions that invited respondents to provide a "yes", "no" or "not sure" answer). 
Participants could give ideas about what kind of topics to cover. One key decision made as a result of this dialogue was to make the survey open to responses from people with disabilities themselves. At first the core research team had thought of doing the survey only amongst respondents without disability. However, at the workshop, participants reflected on how people with disabilities themselves may hold prejudiced views about other people with disabilities or other types of disabilities.

The survey was made available as an online survey (using Qualtrics as the host site) and a paper questionnaire, and was translated into four of the most commonly spoken languages in South Africa: English, Afrikaans, isiXhosa and isiZulu. We ran the survey during 2016, and received a total of 1990 responses from South Africans from all walks of life. Of these, 125 respondents reported having a disability, while 1865 respondents reported being South Africans without disability. The demographic characteristics of the respondents are depicted in Table 1.1. It is worth noting that-while we included race as a category of optional identification for

Table 1.1 Demographics of survey respondents

\begin{tabular}{|c|c|c|}
\hline & $\begin{array}{l}\text { People with disability only (N } \\
=125)\end{array}$ & $\begin{array}{l}\text { People without disability } \\
\text { only }(N=1865)\end{array}$ \\
\hline Age range & $18-76$ & $18-59$ \\
\hline Mean age & 26 yrs & $24.4 \mathrm{yrs}$ \\
\hline Gender & $\begin{array}{l}35 \% \text { male } \\
65 \% \text { female }\end{array}$ & $\begin{array}{l}43 \% \text { male } \\
57 \% \text { female }\end{array}$ \\
\hline Sexual orientation & $\begin{array}{l}68 \% \text { heterosexual } \\
7 \% \text { gay or lesbian } \\
10 \% \text { bisexual } \\
15 \% \text { asexual }\end{array}$ & $\begin{array}{l}75 \% \text { heterosexual } \\
3 \% \text { gay or lesbian } \\
4 \% \text { bisexual } \\
18 \% \text { asexual }\end{array}$ \\
\hline Self-identified race & $\begin{array}{l}33 \% \text { Black } \\
46 \% \text { White } \\
9 \% \text { Coloured } \\
8 \% \text { Indian } \\
4 \% \text { Other }\end{array}$ & $\begin{array}{l}46 \% \text { Black } \\
40 \% \text { White } \\
8 \% \text { Coloured } \\
4 \% \text { Indian } \\
2 \% \text { Other }\end{array}$ \\
\hline $\begin{array}{l}\text { Most common languages } \\
\text { spoken }\end{array}$ & $\begin{array}{l}44 \% \text { English } \\
25 \% \text { Afrikaans } \\
7 \% \text { Zulu } \\
7 \% \text { Tsipedi }\end{array}$ & $\begin{array}{l}35 \% \text { English } \\
24 \% \text { Afrikaans } \\
10 \% \text { Xhosa } \\
9 \% \text { Zulu }\end{array}$ \\
\hline Education & $\begin{array}{l}57 \% \text { had completed high } \\
\text { school } \\
23 \% \text { had at least one degree } \\
\text { qualification }\end{array}$ & $\begin{array}{l}51 \% \text { had completed } \\
\text { high school } \\
23 \% \text { had at least one } \\
\text { degree qualification }\end{array}$ \\
\hline
\end{tabular}


respondents-we did not conduct any analyses by self-identified racial "group". We included racial identification to get a sense of whether our sample was at all representative of the demographics of the country, and the demographics of the country are based on a national Census which utilises racial categories (although the validity of doing so is debated). However, race was not relevant for, nor the proposed subject of, any of our subsequent analyses, and nor was language.

Survey studies are useful in that they collect specific data across a broad range of respondents. A survey provides numerical data which can be explored for statistical trends, as well as qualitative data that can be explored for themes across all responses. However, survey studies do have limitations. One key limitation is that although surveys enable the collection of data from a broad range of respondents, this is often at the expense of detailed, subjective responses about individual experiences. The survey was a useful way of investigating societal attitudes across a large number of respondents, but it would not have been a useful way of capturing the personal experiences of people with physical disabilities themselves. To do this latter work, a different method for collecting data was needed which would allow participants to make their own decisions about what personal stories to share.

\section{Study 2: The Experiences of People with Physical Disabilities}

After attending the participants' workshop, a total of 13 participants (six women and seven men) agreed to be interviewed about their personal experiences of sexuality and relationships as a person with a physical disability. This is an intensely private topic, so it was important that this was done in a sensitive way, respectful of what the participants felt comfortable sharing about themselves. As a core research team, we suggested using Photovoice as a method for inviting participants to tell their stories.

Photovoice (first developed by Wang \& Burris, 1997) is a method of generating research data that is participatory, because it allows the person being researched to set their own agenda about what the topic of exploration is by facilitating the expression of their personal stories and meanings. Photovoice involves participants taking or using photographs as a way of recording aspects of their daily lives and experiences relevant to the issue being investigated. These photographs then act as material 
for eliciting personal narratives during a research interview. The participants become co-researchers in that they are invited to act like journalists to their own personal lives and experiences; creating and sharing their own recorded, visualised realities. Photovoice allows for the generation of research knowledge which is centred on the personal experiences of individuals and their interactions with their social and physical environment (Letts, 2003).

The six women and seven men who took part in this study were each given digital cameras. At the participants' workshop, a discussion session was dedicated to this Photovoice study and what each person was invited to do. The participants were invited to use other media, if preferred, such as drawing or writing. The participants were given three months to collect photographs or other material, after which they would then be interviewed individually. This activity invited participants to reflect upon their past and present experiences. With matters of sexuality, they were invited to take photographs that represented or were symbolic of their experiences and their feelings and thoughts about their sexual identity. They were not asked to take explicit photographs, but rather photographs that were symbolic of or represented their personal experiences (like the ones included earlier in this chapter). Thus, this process invited the photographer to look both inside themselves (by thinking about what photo they wanted to take and what it meant to them) as well as look outside for inspiration for what would capture that meaning or experience. Photovoice thus involves an interaction between the internal self and the outside world. This also echoes the very nature of social and intimate relationships - the self in relation to the other.

At the interview, participants were asked to bring a selection of up to five photographs (or drawings or other material), which then formed the basis for discussion during the interview. The topic was sexuality, relationships and sexual health. However, instead of the interview having a pre-determined set of questions that each participant was then asked, each interview was different, focusing as it did on the individual's unique personal experience and history.

The aim of the interviews was to generate research data which could then be analysed. However, as participatory action research aims to achieve, the purpose is not just to collect data for the sake of it, but to also take action: to do something with that data. The photovoice interviews elucidated a lot of rich material and images, which we could then use as 
a resource to do advocacy for change. We will include some of what we learned in these interviews in the remaining chapters of this book.

In addition to these two studies, we also produced a short, 16-minute documentary film about disability and sexuality in South Africa, featuring four of the participants who took part in this project. We have created a website on the project, which features some of the work that has been done, including the film and some of the photographs that were taken. The website is: www.disabilityandsexualityproject.com. Go and have a look!

\section{Outline OF THE BoOK}

We have included some of the personal stories, photographs, drawings and poems which arose from the project, in this book. We have also written the chapters with some of the participants as co-authors. In publishing the personal stories of the participants we worked with, we sometimes name individuals that speak or are being referred to. Typically, in research, pseudonyms tend to be used when reporting on results, in order to protect anonymity and confidentiality. However, in taking a participatory research approach, our participants are also co-researchers and co-authors and so they made their own choices as to whether they wanted to use a pseudonym (to protect their identity) or use their real names. In this book we use the names that participants have chosen and agreed to be used (whether actual name or pseudonym).

Chapter 2-Disability and sexuality: In Chapter 2 we will explore some of the myths and misconceptions that exist about the sexual lives of people with phsycial disabilities. We look particularly at the myth of asexuality, and we report on data from the survey study showing whether this myth exists in the views of South Africans without disability. We also look at the kinds of stereotypes about people with physical disabilities that survey respondents used. The chapter then looks at how this myth of asexuality means that many young people with physical disabilities are excluded from sexual health education, may be vulnerable to sexual abuse and exploitation, and generally feel excluded from the world of dating and relationships. We draw on existing research knowledge, as well as the pictures and personal stories of participants in our research project.

Chapter 3-Cleone's story: In this chapter, Cleone, a project participant, writes about how acquiring a disability in her early adulthood impacted on her sense of femininity and sexuality. Cleone was a model 
prior to acquiring a physical disability and she writes about attractiveness and the body, and her journey to reclaim her sense of femininity and sexuality.

Chapter 4-Disability and femininity: In Chapter 4 we will explore the intersections of disability and femininity. We will look at how disability influences the way women with physical disabilities are viewed and view themselves as sexual beings, using a combination of background literature and qualitative data from the photovoice study described above. We have also included pictures, written texts and stories produced by some of the female participants on the project.

Chapter 5-Rosabelle's story: In this short chapter, Rosabelle, one of the project participants, writes a personal story about how sport had a positive impact on her self-confidence, body image, and ultimately her sense of sexuality.

Chapter 6-Disability and masculinity: In Chapter 6 we will explore the intersections of physical disability and masculinity. We will look at how physical disability influences how men are viewed by others, and how men with physical disabilities view themselves as masculine and as sexual beings. We also look at the influence of culture on masculinity in the South African context. We draw on existing research knowledge, as well as the pictures and personal stories of some of the male participants in our research project.

Chapter 7-Bongani's story: In this chapter, Bongani writes about growing up with a physical disability in a Zulu family, as well as in the context of a "special school". He reflects on what disability has meant for his developing sense of himself as a young man, his sexuality and relationships, and his wishes for the future.

Chapter 8-Sexual and reproductive health: In Chapter 8, we will investigate some of the social (e.g. negative attitudes about sexuality and parenthood) and structural (e.g. inaccessible health care facilitates) barriers that people with physical disabilities face toward leading a pleasurable, safe and healthy sexual life. We do this by presenting an accessible review of the existing research literature, a summary of relevant survey evidence, and the use of the personal stories of our participants.

Chapter 9-Vic's story: In this chapter, Vic, a project participant, writes about getting married and becoming a father after having acquired a serious physical disability in an accident. He writes about how he and his wife underwent IVF to have two children. He also writes about the at 
times inappropriate reactions and questions from others about his wife's pregnancy and his sexuality.

Chapter 10-Reflections on the project: In this final chapter, we will reflect on the project and what has been learnt. The chapter also includes reflections from the participants themselves about what their experience has been in taking part in the project.

\section{A Note on the Politics of Voice}

The group of people who are editors of this book make up a diverse group. Some of us are men, some women, some identify as having a disability, some do not. Some identify as LGBT, some do not. We are also diverse in terms of where we live (half of us live in Africa, half do not), our heritage and countries of origin, and our "race" or skin colour. Most, but not all, of us are academics and researchers, and all of us are committed to disability inclusion globally, but with a special interest in African issues. However, we are not the same as our participants and we cannot speak for them. We cannot speak about "disability" as a wholewe all have our own limited experience. One of the key lessons of disability activism is that nobody can or should speak on behalf of anyone else. As far as possible, people should speak for themselves, and should not be spoken about-instead everyone should be part of the conversation. In putting this book together, we have tried to work according to this principle, and so, unusually for a research project, we have people who were being researched actually writing some of the material themselves. We are proud to work in this way. But it is also important that we are clear that we, as the editorial collective, made key choices about this book, and how to put it together-we have designed the book and edited it. We cannot avoid the fact that we have shaped the book, that we are often speaking about people, and that our perspectives are not the only ones. We hope that readers will think critically about this issue and will engage with us on it and all other issues.

\section{REFERENCES}

Braathen, S. H., Rohleder, P., \& Azalde, G. (2017). Sexual and reproductive health and rights of girls with disabilities. A report written for the United Nations Office of the Special Rapporteur on the Rights of People with 
Disabilities. Retrieved from https://www.sintef.no/en/projects/literature-rev iew-sexual-and-reporductive-health-a/.

Carew, M., Braathen, S., Swartz, L., Hunt, X., \& Rohleder, P. (2017). The sexual lives of people with disabilities within low- and middle-income countries: A scoping study of studies published in English. Global Health Action, 10(1), 1337342.

Collier, J. (1945). United States Indian Administration as a laboratory of ethnic relations. Social Research, 12(3), 265-303.

de Reus, L., Hanass-Hancock, J., Henken, S., \& van Brake, W. (2015). Challenges in providing HIV and sexuality education to learners with disabilities in South Africa: The voice of educators. Sex Education, 15, 333-347. https:// doi.org/10.1080/14681811.2015.1023283.

Freire, P. (1972). Pedagogy of the oppressed. Harmondsworth, UK: Penguin.

Goodley, D., \& Lawthom, R. (2005). Epistemological journeys in participatory action research: Alliances between community psychology and disability studies. Disability \& Society, 20(2), 135-151.

Groce, N., Rohleder, P., Eide, A., MacLachlan, M., Mall, S., \& Swartz, L. (2013). HIV issues and people with disabilities: A review and agenda for research. Social Science and Medicine, 77, 31-40.

Hergenrather, K., \& Rhodes, S. (2007). Exploring undergraduate student attitudes toward persons with disabilities: Application of the disability social relationship scale. Rehabilitation Counseling Bulletin, 50(2), 66-75.

Kagan, C., Burton, M., Duckett, P., Lawthom, R., \& Siddiquee, A. (2011). Critical community psychology. Chichester: Wiley.

Kagan, C., Burton, M., \& Siddiquee, A. (2008). Action research. In C. Willig \& W. Stainton-Rogers (Eds.), The Sage handbook of qualitative research in psychology (pp. 32-53). London: Sage.

Leonardi, M., Bickenbach, J., Ustun, T. B., Kostanjsek, N., \& Chatterji, S. (2006). The definition of disability: What is in a name? Lancet, 368(9543), $1219-1221$.

Letts, L. (2003). Occupational therapy and participatory research: A partnership worth pursuing. American Journal of Occupational Therapy, 57(1), 77-87.

Lewin, K. (1946). Action research and minority problems. Journal of Social Issues, 2(4), 34-46.

Malacrida, C. (2009). Performing motherhood in a disablist world: Dilemmas of motherhood, femininity and disability. International Journal of Qualitative Studies in Education, 22(1), 99-117.

Marini, I., Chan, R., Feist, A., \& Flores-Torres, L. (2011). Student attitudes toward intimacy with persons who are wheelchair users. Rebabilitation Research, Policy \& Education, 25(1), 15-26. 
Nguyen, T. T. A., Liamputtong, P., \& Monfries, M. (2016). Reproductive and sexual health of people with physical disabilities: A metasynthesis. Sexuality and Disability, 34(1), 3-26.

O'Dea, S. M., Shuttleworth, R. P., \& Wedgwood, N. (2012). Disability, doctors and sexuality: Do healthcare providers influence the sexual wellbeing of people living with a neuromuscular disorder? Sexuality and Disability, 30(2), 171185.

Peta, C. (2017). Disability is not asexuality: The childbearing experiences and aspirations of women with disability in Zimbabwe. Reproductive Health Matters, 25(50), 10-19. https://doi.org/10.1080/09688080.2017. 1331684.

Rapoport, R. N. (1970). Three dilemmas in action research: With special reference to the Tavistock experience. Human Relations, 23(6), 499-513.

Shisana, O., Rehle, T., Simbayi, L. C., Zuma, K., Jooste, S., Zungu, N., ... Onoya D. (2014). South African National HIV prevalence, incidence and behaviour survey, 2012. Cape Town: HSRC Press.

Statistics South Africa. (2014). Census 2011: Profile of persons with disabilities in South Africa. Pretoria: Statistics South Africa. Retrieved from http://www.sta tssa.gov.za/publications/Report-03-01-59/Report-03-01-592011.pdf.

United Nations. (2006). Convention for the Rights of Persons with Disability (UNCRPD). Geneva: United Nations. Retrieved from https://www.un.org/ development/desa/disabilities/convention-on-the-rights-of-persons-with-dis abilities/convention-on-the-rights-of-persons-with-disabilities-2.html.

Wang, C., \& Burris, M. A. (1997). Photovoice: Concept, methodology, and use for participatory needs assessment. Health Education \& Behavior, 24(3), 369-387.

World Health Organization [WHO]. (2001). International classification of functioning, disability and health (ICF). Geneva: WHO.

World Health Organization, W. (2006). Defining sexual health. Retrieved from http://www.who.int/reproductivehealth/topics/sexual_health/sh_def initions/en/.

World Health Organization and The World Bank. (2011). World report on disability. Geneva: WHO and The World Bank. 
Open Access This chapter is licensed under the terms of the Creative Commons Attribution 4.0 International License (http://creativecommons.org/licenses/ by $/ 4.0 /$ ), which permits use, sharing, adaptation, distribution and reproduction in any medium or format, as long as you give appropriate credit to the original author(s) and the source, provide a link to the Creative Commons license and indicate if changes were made.

The images or other third party material in this chapter are included in the chapter's Creative Commons license, unless indicated otherwise in a credit line to the material. If material is not included in the chapter's Creative Commons license and your intended use is not permitted by statutory regulation or exceeds the permitted use, you will need to obtain permission directly from the copyright holder.

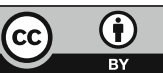

